\title{
Advances in the use of topical imiquimod to treat dermatologic disorders
}

\author{
Francesco Lacarrubba \\ Maria Rita Nasca \\ Giuseppe Micali \\ Dermatology Clinic, University of \\ Catania, Italy
}

\begin{abstract}
Imiquimod (IQ) is an immune-response modifying agent, first approved by FDA for the topical treatment of external genital and perianal warts in 1997. It induces, through stimulation of Toll-like receptors (TLRs) localized on the surface of antigen-presenting cells, synthesis and release of several endogenous pro-inflammatory cytokines such as interferon- $\alpha$ (IFN- $\alpha$ ), tumor necrosis factor- $\alpha$ (TNF- $\alpha$ ) and interleukins (IL) 6 and 12, which in turn stimulate both the innate and acquired immune pathways, resulting in upregulation of natural antiviral and antitumor activity. IQ 5\% cream has been used for the treatment of a wide variety of dermatologic conditions in which the immune system is thought to play a role in regression of the disease. In some disorders, such as genital and perianal warts, actinic keratoses, basal cell carcinomas, Bowen's disease and molluscum contagiosum, relative safety and efficacy are supported by randomized controlled trials of IQ. However, it is common for patients to experience local skin reactions, which can range from mild to severe in intensity, but usually resolve 1-2 weeks after interrupting treatment. Additional randomized trials are encouraged to assess safety and efficacy of IQ in the treatment of an even wider range of cutaneous disorders.
\end{abstract}

Keywords: imiquimod, immune response modifiers

\section{Introduction}

Imiquimod (IQ) is a member of a class of immune-response modifying agents, first approved by FDA for the topical treatment of external genital and perianal warts in 1997.

The effect of IQ cream on immunity has suggested its possible use in the treatment of a wide variety of dermatologic conditions in which the immune system is thought to play a role in regression of the disease (Tyring et al 2002; Vender and Goldberg 2005).

In this review recent literature regarding mechanism of action, clinical applications and safety of IQ will be discussed.

\section{Mechanism of action}

IQ (1-[2-methylpropyl]-1H-imidazo[4,5-c]quinolin-4-amine) is a synthetic imidazoquinoline amine that enhances, through cytokine induction, both the innate and acquired immune pathways, resulting in immunomodulating, antiviral and antitumor effects.

The mechanism of action of IQ is mainly related to the binding and stimulation of Toll-like receptors (TLRs), that are located on the surface of antigen-presenting cells, and serve to recognize and defend against invading pathogens (Chang et al 2005; Ceilley and Del Rosso 2006; Patel et al 2006). IQ is a potent TLR-7 agonist which induces synthesis and release of several endogenous pro-inflammatory cytokines from Langerhans cells, monocytes/macrophages and dendritic cells. These include interferon- $\alpha$ (IFN- $\alpha$ ), tumor necrosis factor- $\alpha$ (TNF- $\alpha$ ) and interleukins (IL) 1, 6, 8, 10 and 12, which in turn activate and perpetuate cell-mediated immune responses primarily mediated by lymphocytes CD4+ and CD8+ (Sauder 2003; Schiller et al 2006). In particular, IQ stimulates natural killer cells of the innate immune system and activates $T$ helper cell type 1 and cytotoxic T lymphocytes responsible for killing virus-infected and 
tumor cells, as well as establishing immunological memory (Garland 2003).

Immune-system induction is believed to be responsible for both antiviral and antitumor activity of IQ. However, recent studies have demonstrated that IQ may directly stimulate production of pro-apoptotic signalling. As a result, virus-infected keratinocytes and/or neoplastic cells are driven into apoptosis and eliminated. This process is mediated via death receptors, including Fas Receptor (FasR), a member of the tumor necrosis factor receptor family (Berman et al 2003). When FasR binds its ligand, namely Fas ligand (FasL), a cascade of events follows, including caspase activation, ultimately eventuating in cellular death. In a vehicle-controlled study, IQ induced expression of FasR in basal cell carcinoma (BCC) cells, leading to cell apoptosis. Normally, BCC cells fail to express FasR, thus preventing cell apoptosis via FasR-Fas ligand interaction (Berman et al 2003; Ceilley and Del Rosso 2006).

\section{Clinical trials}

IQ has been reported to be safe and effective in the treatment of a number of skin disorders (Table 1); however, the clinical literature is replete with case reports, limited case series and open label trials. This review will focus on those conditions in which IQ efficacy is supported by at least one randomized controlled trial (RCT).

\section{External genital and perianal warts}

IQ 5\% cream is FDA approved for the treatment of external genital and perianal warts. Its efficacy in these disorders has been demonstrated in several RCTs (Beutner et al 1998; Edwards et al 1998; Perry and Lamb 1999; Garland et al 2001; Sauder et al 2003; Scheinfeld and Lehman 2006).

In the largest RCT (Edwards et al 1998), 311 patients 18 years of age and older with external genital/perianal warts were randomized to 3 arms (109:102:100) IQ 5\% cream, IQ $1 \%$ cream or vehicle 3 times per week for a maximum of 16 weeks. Complete clearance (absence of lesions) was achieved in $50 \%$ of IQ $5 \%$ patients, $21 \%$ of IQ $1 \%$ patients and $11 \%$ of placebo patients. There was a significantly better complete clearance response in female patients compared to males (72\% vs 33\% respectively) among the IQ 5\% group. The mean time for complete clearance ranged from 8 weeks for women to 12 weeks for men. Recurrence rate of at least 1 wart for patients treated with IQ 5\% was 13\% (12 weeks after treatment was stopped).

In an international open-label multicentre phase IIIB trial (Garland et al 2001) consisting of 943 patients from 114 clinic sites in 20 countries, IQ 5\% cream was applied 3 times per week for up to 16 weeks with an overall complete clearance rate of nearly $48 \%$. Recurrence rate at 6 -months follow up was $23 \%$. This study also confirmed a better clinical outcome in females $(65 \%)$ compared to males (44\%). The authors have hypothesized that the different outcome might be related to more incomplete keratinization of vulvar epithelium compared to that of male genitalia (Tyring et al 2002). The semi-occlusive effect of the foreskin has also played a role in the higher clearance rates observed among uncircumcised compared to circumcised individuals (Tyring et al 2002).

In another RCT (Beutner et al 1998) IQ 5\% cream was applied once daily for up to 16 weeks. Complete wart clearance occurred in $52 \%$ of patients, with $19 \%$ wart recurrence at a 12 -week follow-up. These results are similar to those obtained with 3 applications/week (Edwards et al 1998; Garland et al 2001). Therefore, 3 times per week treatment schedule is recommended because of a relatively lower rate of side effects (Perry and Lamb 1999; Gupta et al 2004; Chang et al 2005; Scheinfeld and Lehman 2006).

Topical IQ appears to be less effective in immunosuppressed patients. In a RCT, 97 male HIV-positive patients with genital warts and receiving no antiretroviral therapy, were treated with either IQ or vehicle: the complete response rates were $11 \%$ and $6 \%$ respectively (Gilson et al 1999).

Although further trials are required to compare the efficacy of IQ to other therapies, available data suggest that its efficacy is similar to that of other treatment modalities, including intralesional interferon and podophyllotoxin, but with lower recurrence rates (Perry and Lamb 1999; Garland 2003).

\section{Actinic keratoses}

IQ 5\% cream is also FDA-approved for the treatment of actinic keratoses (AKs) of face and scalp in immunocompetent individuals and its efficacy has been demonstrated by several RCTs followed by three meta-analysis studies (Gupta et al 2005; Falagas et al 2006; Hadley et al 2006).

The first meta-analysis study (Hadley et al 2006) included 5 RCTs with a total of 1293 patients. Complete clearance occurred in $50 \%$ of patients treated with IQ 5\% cream compared to $5 \%$ in the placebo group. The number needed to treat (representing the number of patients needed to be treated with IQ compared to vehicle to obtain one additional beneficial event) was 2.2, showing that IQ 5\% cream is an effective short term therapy.

Another meta-analysis study (Falagas et al 2006) identified 4 RCTs including 1266 patients. In 2 studies IQ or vehicle cream was applied 3 times per week for 16 weeks, in one study applications were 3 times per week for 12 weeks, 
Table I Topical imiquimod in the treatment of dermatologic disorders

\section{Randomized clinical trials}

Genital and perianal warts

Actinic keratosis

Basal cell carcinoma

Bowen's disease

Molluscum contagiosum

Leishmaniasis (plus antimonial agents) (Miranda-Verastegui et al 2005)

\section{Case reports}

Extramammary Paget disease (Cohen et al 2006)

Erythroplasia of Queyrat (Micali, Nasca et al 2003)

Bowenoid papulosis (Goorney and Polorni 2004)

Stucco keratosis (Stockfleth et al 2000)

Porokeratosis of Mibelli (Jain 2006)

Invasive SSC (Martin-Garcia 2005)

Verrucous carcinoma (Schalock et al 2006)

Metastatic melanoma (Wolf et al 2003)

Cutaneous T-Cell lymphoma (Didona et al 2004)

Granuloma annulare (Badavanis et al 2005)

Infantile hemangioma (Hazen et al 2005)

Genital herpes (Brummitt 2006)

Elastosis perforans serpiginosa (Kelly and Purcell 2006)

Pyogenic granuloma (Goldenberg et al 2006)

Langerhans cell hystiocytosis (Taverna et al 2006)

Lymphomatoid papulosis (Hughes 2006)

Angiolymphoid hyperplasia (Redondo et al 2004)

Orf (Erbagci, Erbagci et al 2005)

Hyalohyphomycosis (Erbagci, Tuncel et al 2005)

Foreign body reaction (Baumann and Halem 2003)

Trichilemmal carcinoma (Jo, Ko et al 2005)

Eccrine poroma (Jo, Chin et al 2005)

Lip papillomatosis (Rinne et al 2000)

Keratoacanthoma (Di Lernia et al 2004) and in the fourth study, application rate was 2 times per week for 16 weeks. Meta-analysis for these studies showed complete clearance of AKs ranging from 45 to $84 \%$ in patients treated with IQ compared to $0 \%-7 \%$ in the vehicle group $(\mathrm{p}<0.0001)$.

Most authors have observed that patients may experience an increase in the number of AKs within the treatment area at treatment initiation. This phenomenon is thought to be the result of the appearance of sub-clinical lesions rather than the formation of new ones (Falagas et al 2006). Thus IQ's ability to uncover and treat sub-clinical lesions may be considered an additional benefit of treatment with this drug (Falagas et al 2006). Moreover, clearance of AKs is more frequent in patients who developed intense erythema or other local reactions at the application site, suggesting that inflammation is part of the mechanism of action for topical IQ (Falagas et al 2006).

A third meta-analysis study (Gupta et al 2005) of 10 clinical trials (4 RCTs with topical IQ and 6 RCTs with topical fluorouracil) indicated that IQ may have relatively higher efficacy than topical fluorouracil for AKs located on the face and scalp. The mean efficacy rate for each drug (with $95 \%$ confidence interval) was 5-fluorouracil, $52 \pm 18 \%$ ( $\mathrm{n}=6$ studies, $145 \mathrm{sub}$ jects) and IQ, $70 \pm 12 \%$ ( $\mathrm{n}=4$ studies, 393 subjects $)$.
Long-term effectiveness of topical IQ in the treatment of AKs remains to be determined; only one RCT consisted of "long-term" follow-up (25 patients with 1-year follow-up had $10 \%$ recurrence rate) (Stockfleth et al 2002). Moreover, optimal frequency of application and duration of treatment need to be elucidated by further studies.

\section{Basal cell carcinoma}

Topical IQ 5\% cream is FDA-approved for the treatment of small superficial BCCs.

A Cochrane Skin Group analysis of 7 RCTs demonstrated IQ to be effective and well-tolerated in the treatment of both superficial and nodular BCC (Figures 1 and 2), although response rates varied according to number of applications and BCC clinical type (superficial vs nodular) (Bath-Hextal et al 2006).

A multicenter 6-week dose-response trial (Marks et al 2001) on 99 patients with primary superficial BCCs comparing different application regimens of IQ 5\% cream showed histological clearance rates of $100 \%, 88 \%, 73 \%$ and $70 \%$ for twice daily, once daily, 6 times weekly and 3 times weekly regimens, respectively. Another RCT of 128 patients (Geisse et al 2002) compared IQ in different dose regimens versus vehicle for superficial BCCs ranging in size between 0.5 and $2 \mathrm{~cm}^{2}$ for 12 weeks. Clearance rates were respectively $100 \%$, 
(a)

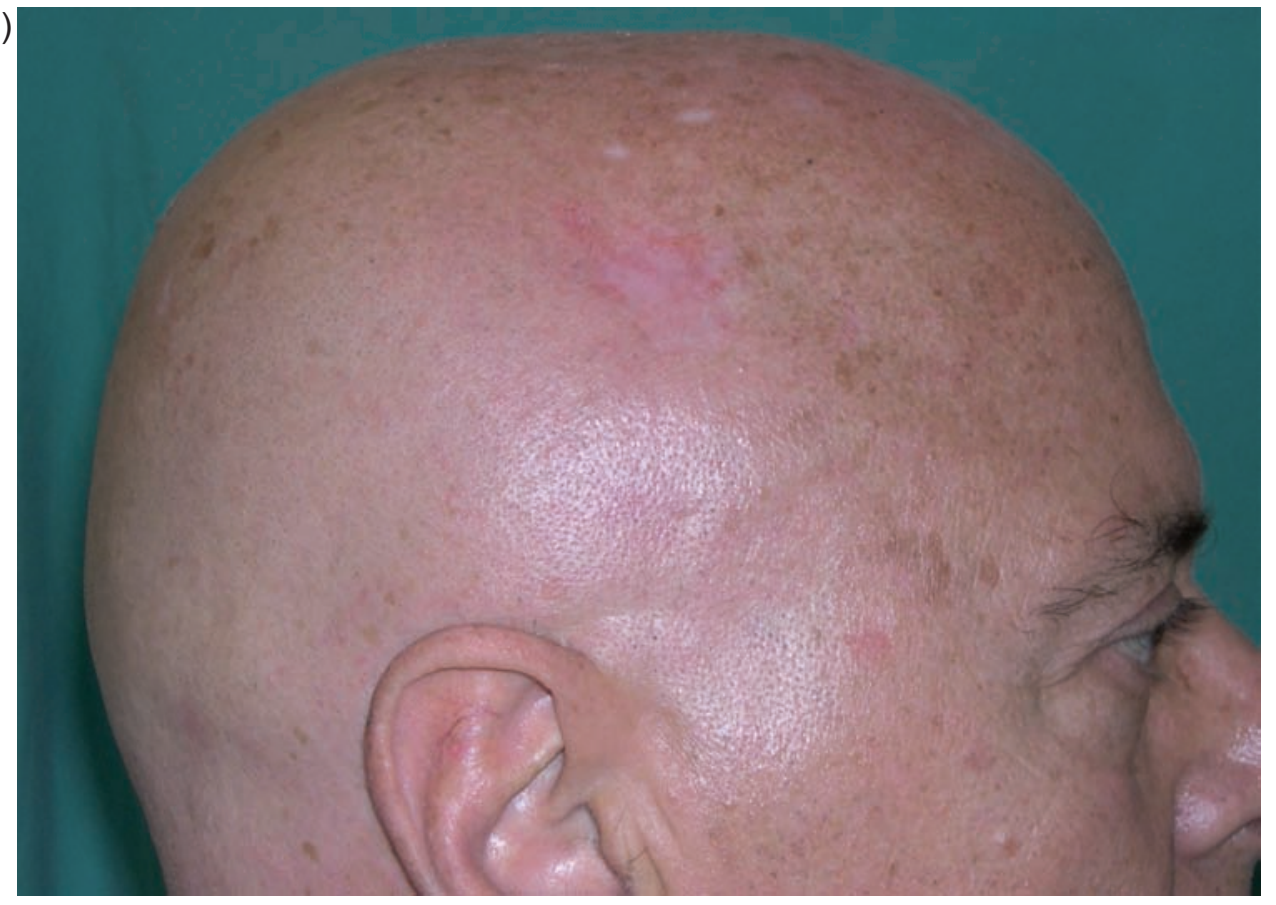

(b)

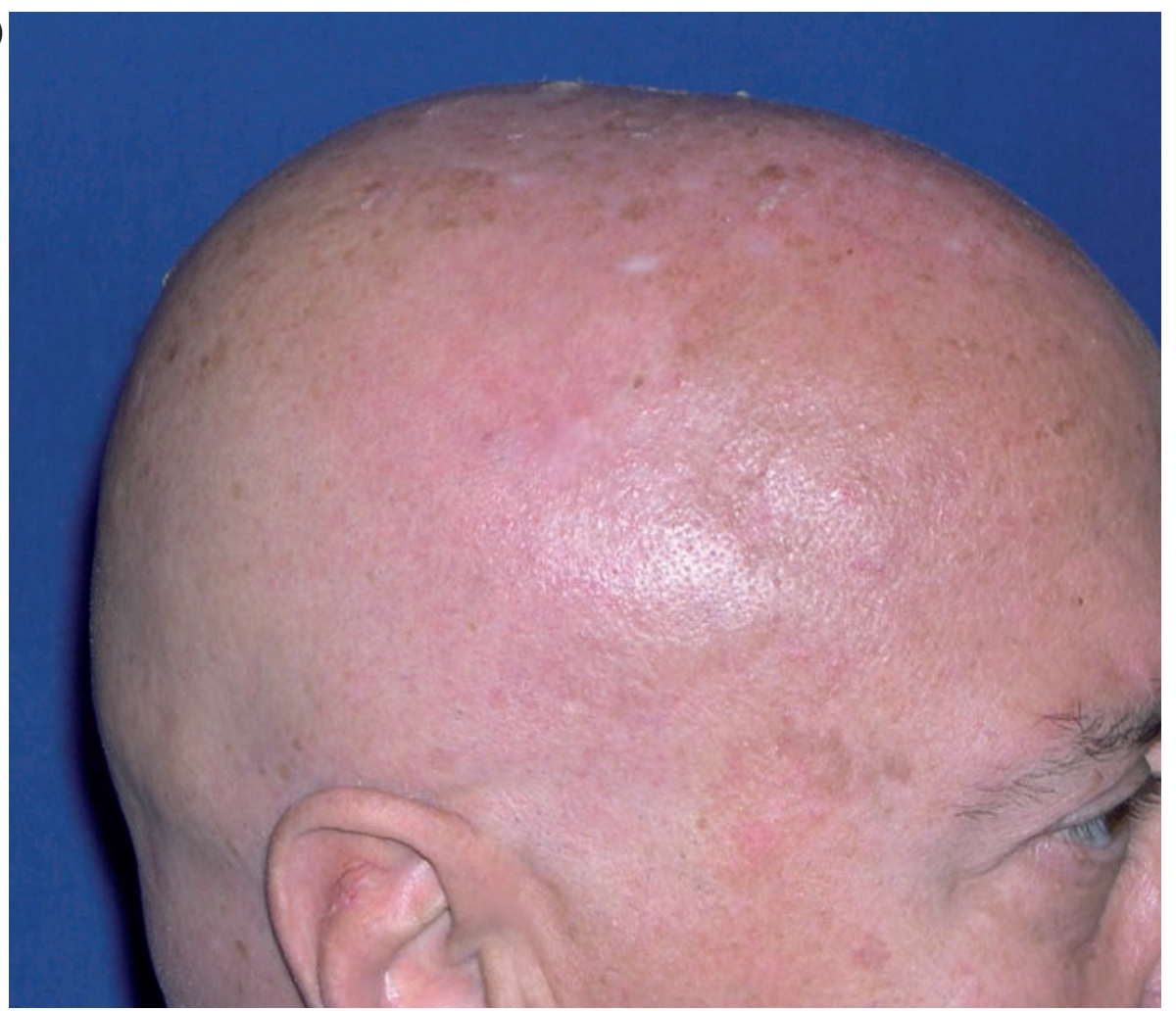

Figure I Superficial BCC of the scalp before (a) and after (b) 8 weeks of treatment with IQ $5 \%$ cream 5 applications/week: complete clearance. 
(a)

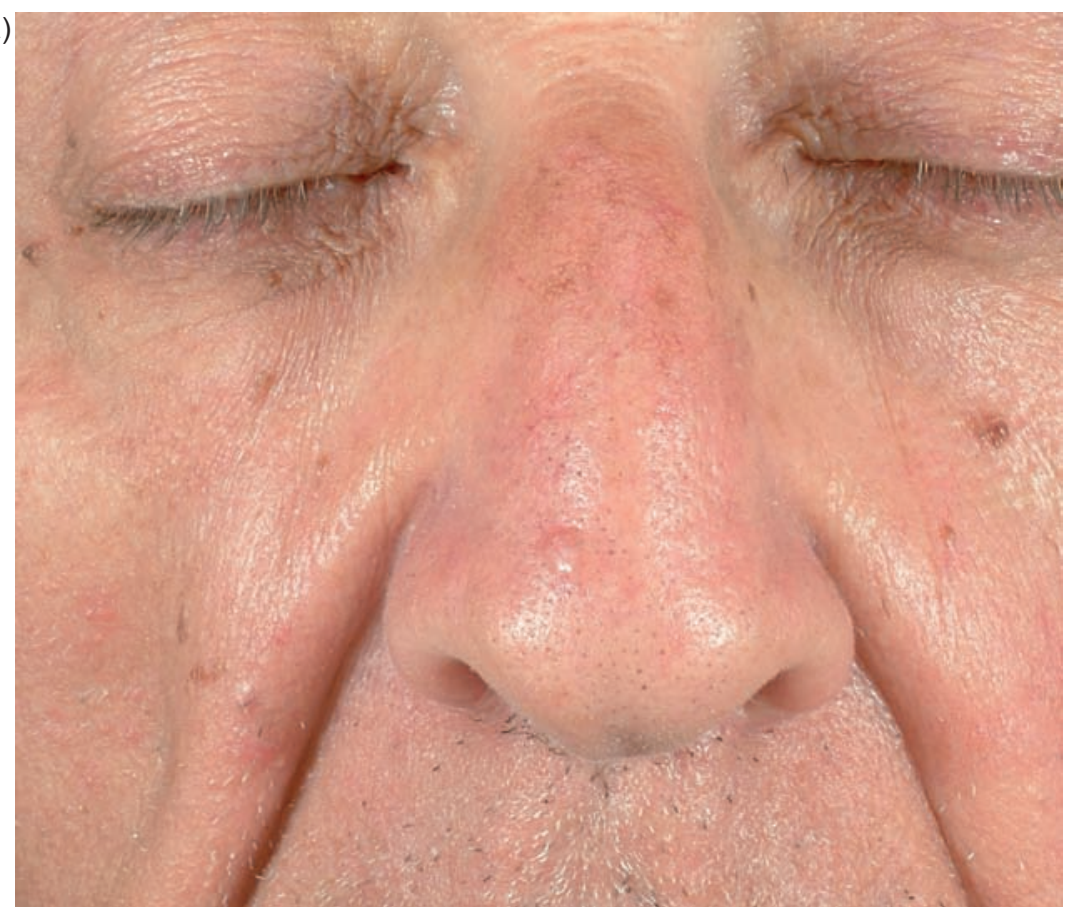

(b)

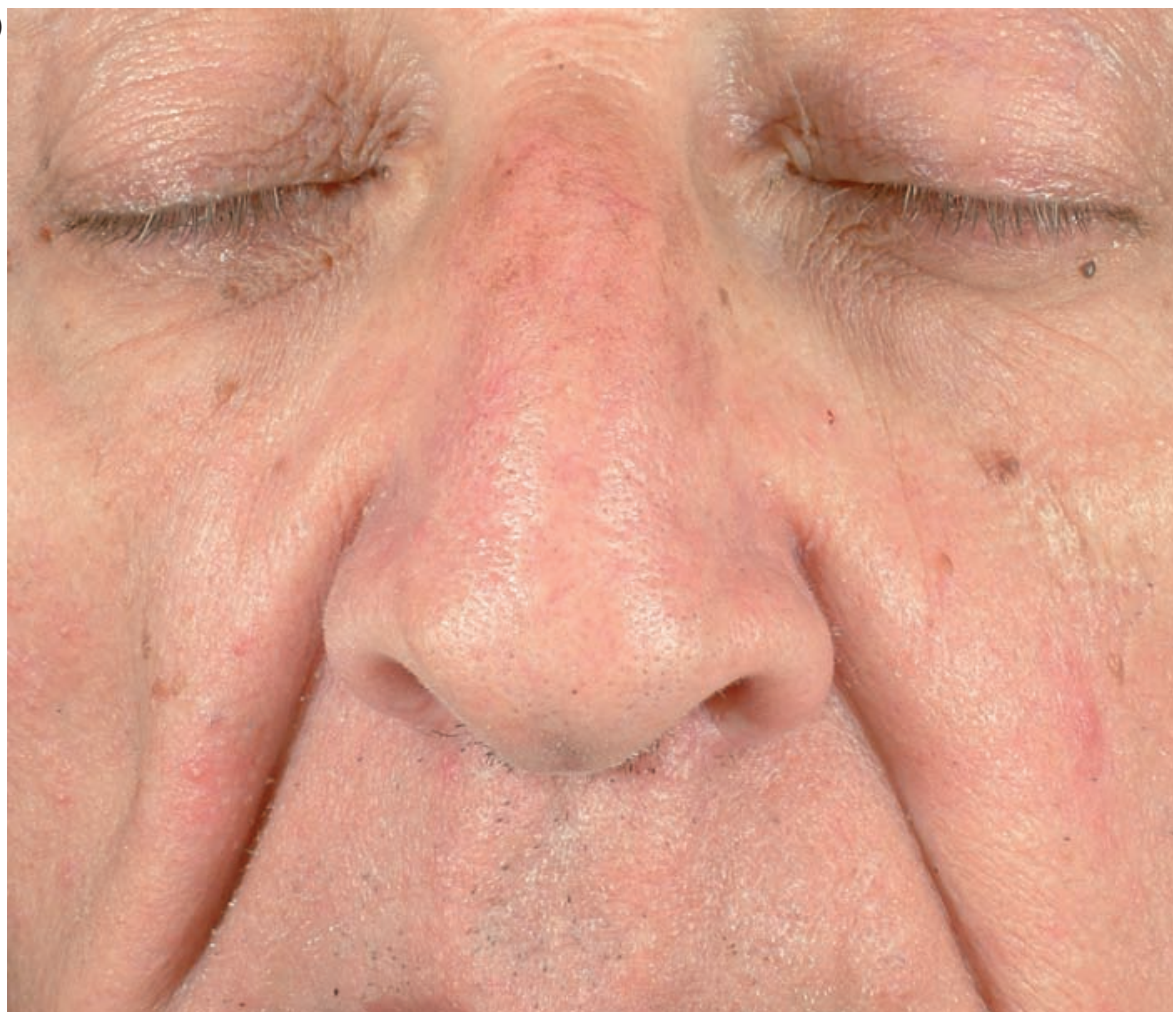

Figure 2 Nodular BCC of the nose before (a) and after (b) 6 weeks of treatment with IQ $5 \%$ cream 5 applications/week: complete clearance. 
$87 \%, 81 \%$ and $52 \%$ for twice daily, once daily, 5 days per week and 3 days per week applications; clearance rate for vehicle was $19 \%$.

A European multicenter study (Schulze et al 2005) of 166 subjects evaluated the clinical efficacy of IQ vs vehicle applied 7 times per weeks for 6 weeks: composite clearance (based on both clinical and histological clearance) was demonstrated in $77 \%$ and $6 \%$ of cases respectively ( $\mathrm{p}<0.001$ ), while histological clearance occurred in $80 \%$ and $6 \%$ of cases, respectively ( $\mathrm{p}<0.001)$. However, in comparing 5 vs 7 applications per week for 6 weeks (Geisse et al 2004), there was no statistically significant or clinically meaningful difference in complete clearance rate between the 2 regimens ( $75 \%$ vs $73 \%$ composite clearance, based on both clinical and histological clearance). Therefore, the 5-times-per-week regimen is preferred, as it is able to provide a balance of efficacy and safety, with fewer treatment-emergent side effects.

Nodular BCCs are more difficult to treat with topical IQ, most likely because of the skin barrier effect and the deeper localization of tumor cells (Chang et al 2005). In a RCT of 92 patients (Shumack et al 2002), the rates of subjects having no histological evidence of BCC in post-treatment excision specimens were $75 \%, 76 \%, 70 \%$ and $60 \%$ after 12 weeks for twice daily, once daily, five days per week or three days per week respectively; treatment failure for vehicle was $87 \%$. These results were confirmed by a 6-week, randomized, openlabel, dose-response study evaluating 4 dosing regimens on 99 patients, in which topical IQ application once daily for 7 days per week resulted in the highest clearance rate $(71 \%)$ (Shumack et al 2002).

Further, two studies comparing the use of topical IQ $5 \%$ cream with and without occlusion in the treatment of superficial and nodular BCCs (Sterry et al 2002) showed no significant difference in early treatment failure for the two application modalities.

Finally, some case reports (no RCTs) have claimed positive responses to topical IQ 5\% in large superficial BCCs (Shumack et al 2004; Micali et al 2005) and multiple BCCs as observed in Gorlin syndrome (Kagy and Amonette 2000; Micali, Lacarrubba, et al 2003).

Indications for the use of topical IQ in the treatment of BCCs are summarized in Table 2. Further long-term studies on the efficacy of topical IQ compared to surgery for BCCs are needed.

\section{Bowen's disease}

A recent RCT has demonstrated the efficacy of topical IQ 5\% cream in the treatment of Bowen's disease (Patel et al 2006). Thirty-one patients with biopsy-proven Bowen's disease were
Table 2 Topical imiquimod in the treatment of BCCs: indications

- Extensive, and/or multifocal, and/or multiple tumours

- Cosmetically sensitive anatomic sites (face)

- History of hypertrophic scarring and/or keloids

- Surgical risk factors (eg, age, associated disorders)

- Psychological condition of the patient

- Patient refusal to undergo surgical procedures

randomly assigned to receive in a double-blind fashion either IQ 5\% cream $(\mathrm{Pt}=15)$ or vehicle $(\mathrm{Pt}=16)$ daily for 16 weeks. At the end of the study, 9 of the 12 patients completing the study in the IQ group (75\%) showed clinical and histological resolution, with no relapse during a 9-month follow-up period, while no improvement was recorded in the placebo group $(p<0.001)$. The authors concluded that the lack of response in the 3 patients treated with IQ was associated with the presence of thick, hyperkeratotic lesions. The results from this single RCT are in agreement with several case reports and non-randomized clinical trials (Mackenzie-Wood et al 2001; Smith et al 2001), but further studies are required.

\section{Molluscum contagiosum}

The efficacy of topical IQ 5\% cream in childhood molluscum contagiosum has been evaluated in a double-blind RCT (Theos et al 2004). Twenty-three children (age 1-9 years) were randomized to receive either IQ cream 5\% $(\mathrm{Pt}=12)$ or vehicle $(\mathrm{Pt}=11) 3$ times a week for 12 weeks. At the end of the study partial clinical clearance $(\geq 30 \%$ clearance of lesions) was noted in $67 \%$ of IQ patients vs $18 \%$ of controls; also, complete clinical clearance was noted in $33.3 \%$ vs $9.1 \%$ of patients, respectively. The mean percentage change in lesion count at week 12 was $-46 \%$ in the IQ group and $+27 \%$ in the vehicle group.

Further, two case series have reported some positive outcomes with topical IQ in treating molluscum contagiosum in both children and adults (Bayerl et al 2003; Hengge and Cusini 2003).

\section{Safety}

In all the RCTs examined in this review topical IQ 5\% cream has demonstrated an acceptable safety profile.

During treatment with topical IQ it is common for patients to experience local skin reactions that range from mild to severe, and may extend beyond the application site onto the surrounding skin. Such reactions include burning, pruritus, pain, tenderness, erythema, oedema, vesicles, erosions, ulcerations, excoriations, exudation and crusting (Figures 3-4). In cases of acute reactions temporary 
(a)

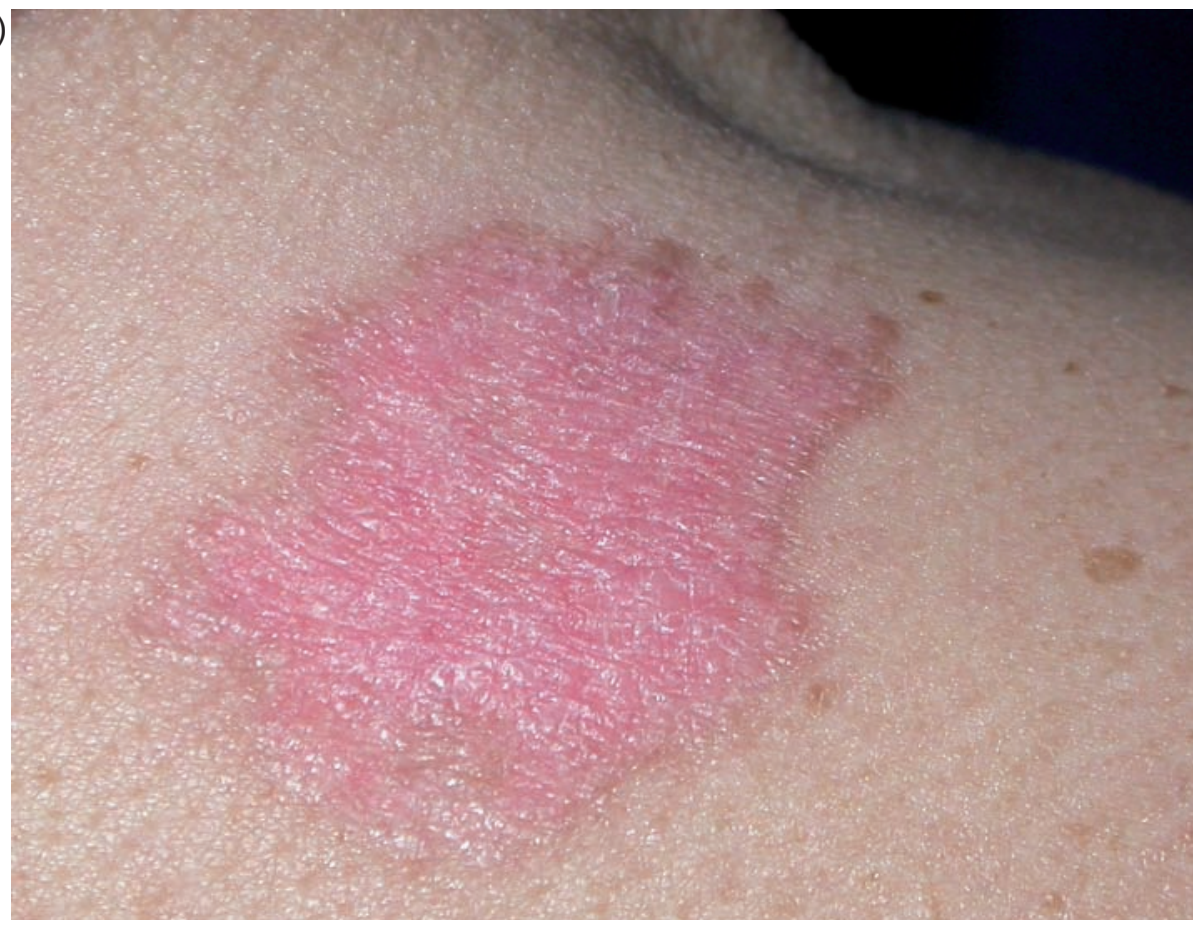

(b)

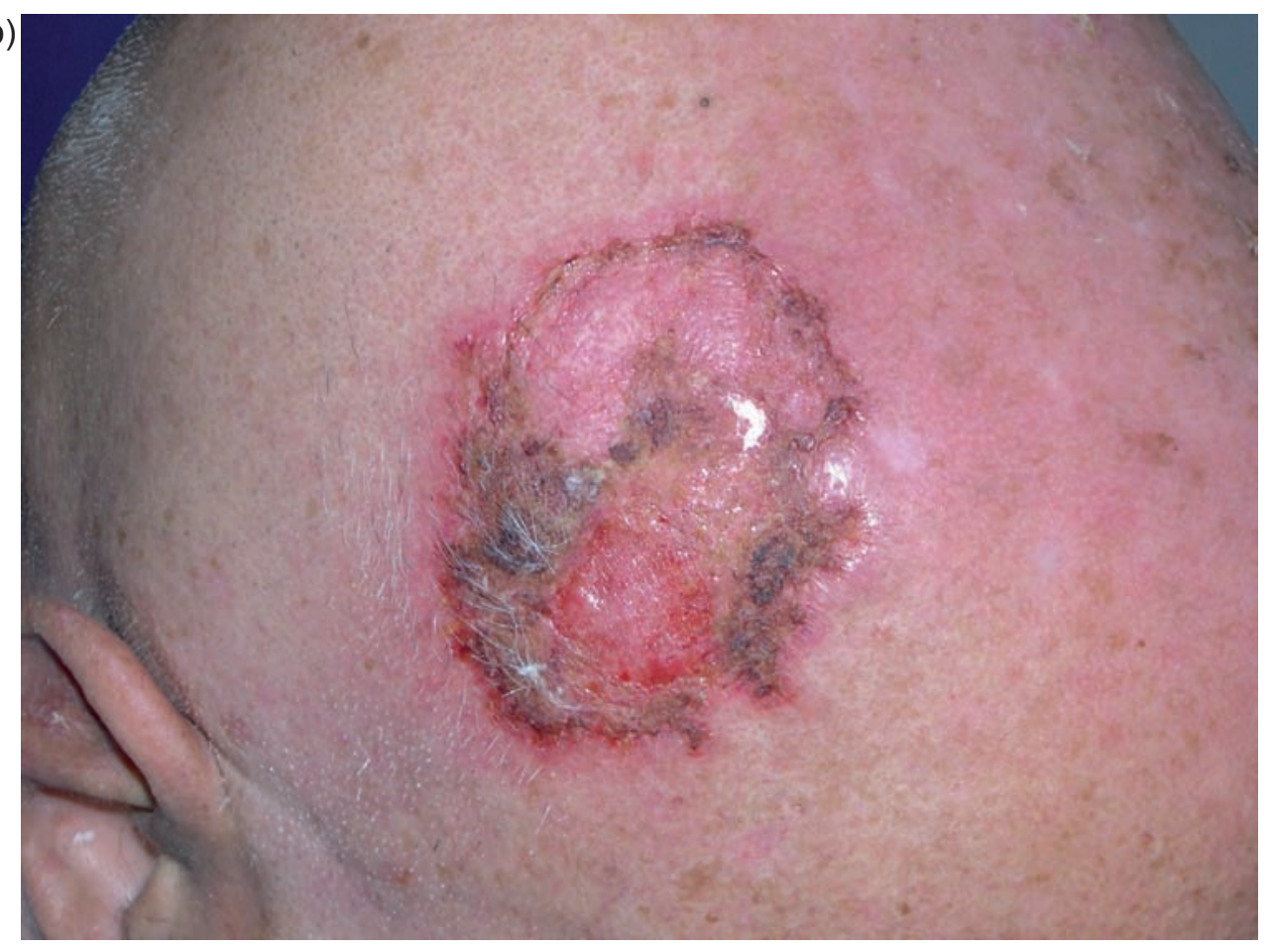

Figure 3 Local skin reactions during treatment with IQ 5\% cream: marked erythema (a), erosion, exudation, and crusting (b). 
(a)

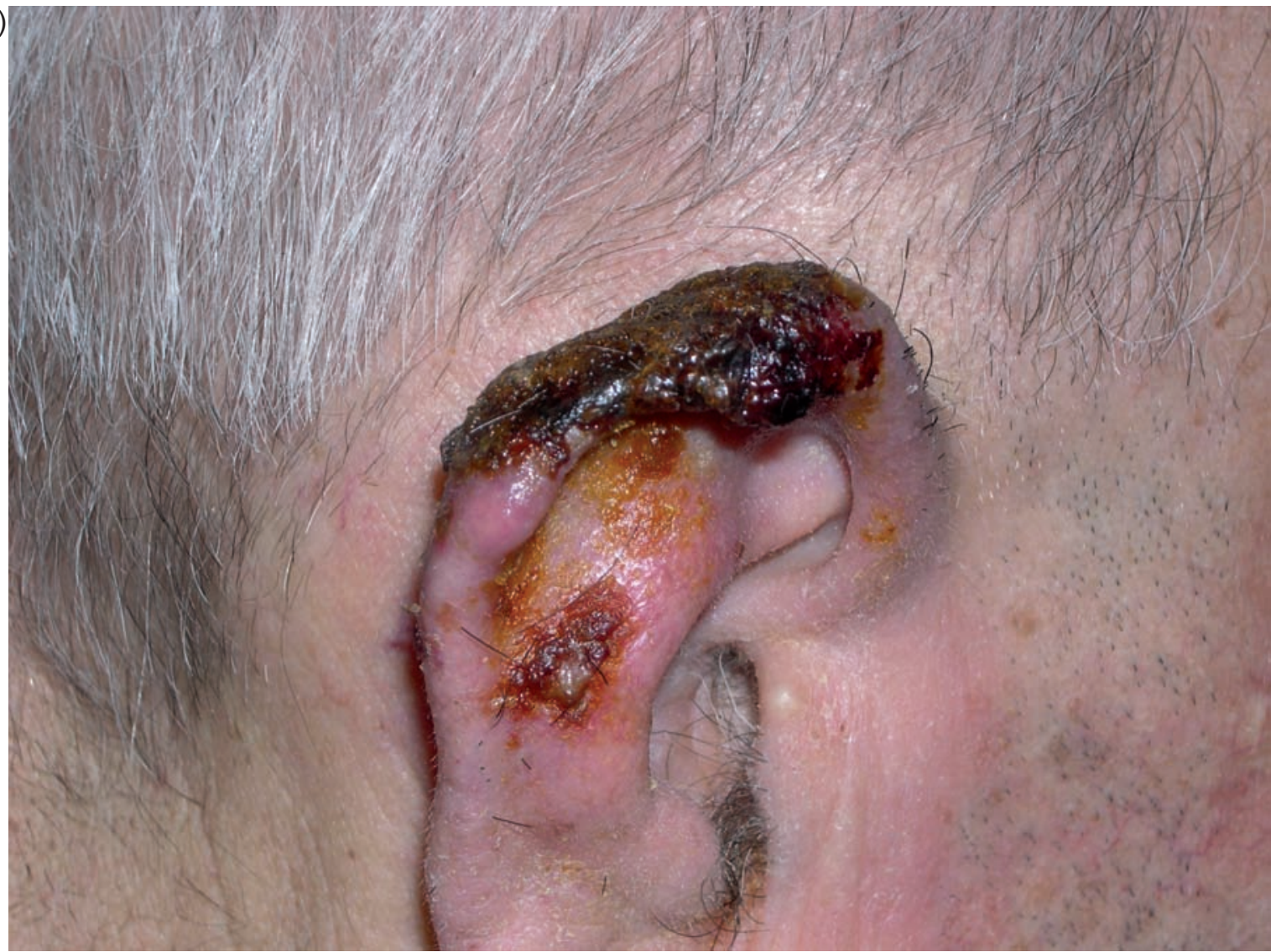

(b)

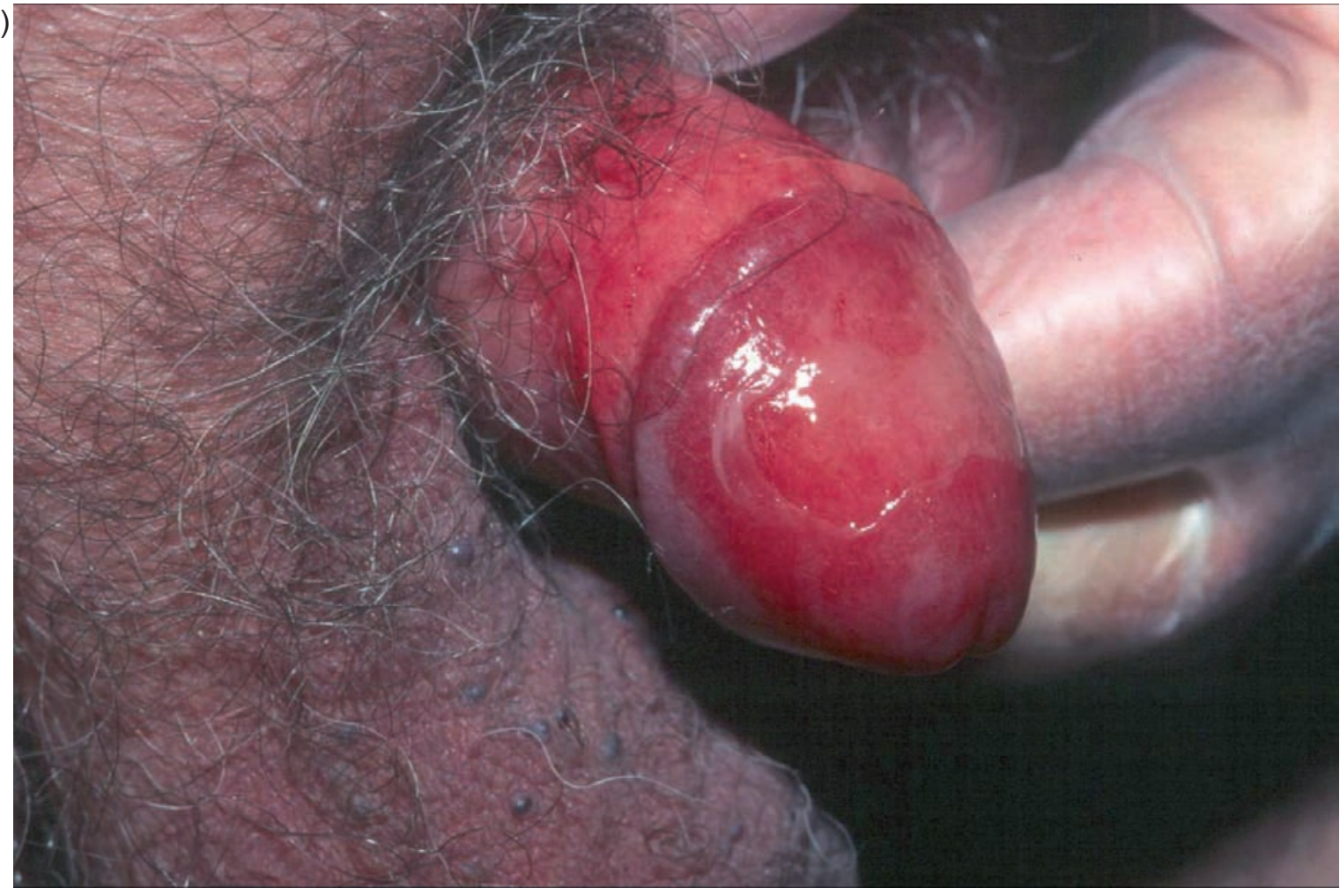

Figure 4 Local skin reactions during treatment with IQ 5\% cream: crusting (a), marked erythema, erosion, and exudation (b). 
discontinuation (generally 1-2 weeks) and application of cold compresses is suggested. Superficial scarring, pigmentary changes, and, rarely, induction of other dermatoses (psoriasis, pemphigus foliaceus, aphthosis, vitiligo, angioedema, eruptive epidermoid cysts) have also been reported (Barton 2004; Gilliet et al 2004; Brown et al 2005; Marty et al 2005; Mashiah and Brenner 2005; Zalaudek et al 2005).

Systemic absorption appears to be minimal and influenza-like or gastrointestinal symptoms (fatigue, fever and chills, arthralgias, myalgias, nausea, diarrhea) or induction of non-dermatologic disorders (chronic neuropathic pain, autoimmune spondyloarthropathy) are rare (Benson 2004; Chang et al 2005; Yi et al 2005).

Exposure to sunlight (including sunlamps) should be avoided or minimized during use of topical IQ because of concern for heightened sunburn susceptibility, therefore the use of sunscreen might be encouraged.

Safety of topical IQ during pregnancy is not established and thus its use is contraindicated. Animal studies did not show any evidence of teratogenicity or fetotoxicity. However, contraception is recommended for women of childbearing age using topical IQ (Scheinfeld and Lehman 2006).

\section{Conclusions}

IQ is a topically active immunomodulatory agent that is currently available as a 5\% cream in single-use sachets for the treatment of some viral and non-viral conditions. It is generally applied sparingly at bedtime from 3 to 5 times per week and washed off in the morning (Chang et al 2005; Scheinfeld and Lehman 2006). For AKs and superficial BCCs, it may be possible to reduce treatment cost by repeated use of a sachet, which is not advised when treating genital warts because of the potential risk of transferring infectious material into the sachet (Patel et al 2006).

The use of IQ in dermatologic disorders presents some advantages: the cream is self-applied by the patient, compared to other therapeutic strategies, avoiding more costly and painful procedures (Perry and Lamb 1999; Bath-Hextal et al 2006); in addition, it provides a non-scarring cosmetic outcome, when compared to surgical procedures. Also, side effects are usually localized to the treatment site and resolve after treatment cessation.

Because of the potential properties of topical IQ, additional RCTs are encouraged to assess its efficacy in the treatment of other cutaneous disorders. Moreover, as the relatively reduced response rate in patients treated with topical IQ is apparently associated with fully keratinized skin, the use of adjuvant therapies to decrease the stratum corneum/epidermis barrier and improve drug penetration and efficacy warrant further investigation (Patel et al 2006).

\section{References}

Badavanis G, Monastirli A, Pasmatzi E, et al. 2005. Successful treatment of granuloma annulare with imiquimod cream 5\%: a report of four cases. Acta Derm Venereol, 85:547-8.

Barton JC. 2004. Angioedema associated with imiquimod. J Am Acad Dermatol, 51:477-8.

Bath-Hextall FJ, Bong J, Perkins W, et al. 2006. Interventions for basal cell carcinoma of the skin (Cochrane review). Cochrane Database Syst Rev, Vol I:

Bayerl C, Feller G, Goerdt S. 2003. Experience in treating molluscum contagiosum in children with imiquimod $5 \%$ cream. Br J Dermatol, 149 Suppl 66:25-9.

Baumann LS, Halem ML. 2003. Lip silicone granulomatous foreign body reaction treated with aldara (Imiquimod 5\%). Dermatol Surg, 29:429-32.

Benson E. 2004. Imiquimod: potential risk of an immunostimulant. Australas $J$ Dermatol, 45:123-4.

Berman B, Sullivan T, De Araujo T, et al. 2003. Expression of Fas-receptor on basal cell carcinomas after treatment with imiquimod $5 \%$ cream or vehicle. Br J Dermatol, 149 Suppl 66:59-61.

Beutner KR, Tyring SK, Trofatter KF Jr, et al. 1998. Imiquimod, a patientapplied immune-response modifier for treatment of external genital warts. Antimicrob Agents Chemother, 42:789-94.

Brown T, Zirvi M, Cotsarelis G, et al. 2005. Vitiligo-like hypopigmentation associated with imiquimod treatment of genital warts. $J$ Am Acad Dermatol, 52:715-16.

Brummitt CF. 2006. Imiquimod 5\% cream for the treatment of recurrent, acyclovir-resistant genital herpes. Clin Infect Dis, 42:575.

Ceilley RI, Del Rosso JQ. 2006. Current modalities and new advances in the treatment of basal cell carcinoma. Int J Dermatol, 45:489-98.

Chang YC, Madkan V, Cook-Norris R, et al. 2005. Current and potential uses of imiquimod. South Med J, 98:914-20.

Cohen PR, Schulze KE, Tschen JA, et al. 2006. Treatment of extramammary Paget disease with topical imiquimod cream: case report and literature review. South Med J, 99:396-402.

Deeths MJ, Chapman JT, Dellavalle RP, et al. 2005. Treatment of patch and plaque stage mycosis fungoides with imiquimod $5 \%$ cream. $J \mathrm{Am}$ Acad Dermatol, 52:275-80.

Didona B, Benucci R, Amerio P, et al. 2004. Primary cutaneous CD30+ T-cell lymphoma responsive to topical imiquimod. $\mathrm{Br} J$ Dermatol, 150:1198-201.

Di Lernia V, Ricci C, Albertini G. 2004. Spontaneous regression of keratoacanthoma can be promoted by topical treatment with imiquimod cream. J Eur Acad Dermatol Venereol, 18:626-9.

Dytoc M, Ting PT, Man J, et al. 2005. First case series on the use of imiquimod for morphoea. Br J Dermatol, 153:815-20.

Edwards L, Ferenczy A, Eron L, et al. 1998. Self-administered topical 5\% imiquimod cream for external anogenital warts. HPV Study Group. Human PapillomaVirus. Arch Dermatol, 134:25-30.

Erbagci Z, Erbagci I, Almila Tuncel A. 2005. Rapid improvement of human orf (ecthyma contagiosum) with topical imiquimod cream: report of four complicated cases. J Dermatolog Treat, 16:353-6.

Erbagci Z, Tuncel AA, Erkilic S, et al. 2005. Successful treatment of antifungal- and cryotherapy-resistant subcutaneous hyalohyphomycosis in an immunocompetent case with topical $5 \%$ imiquimod cream. Mycopathologia, 159:521-6.

Falagas ME, Angelousi AG, Peppas G. 2006. Imiquimod in the treatment of actinic keratosis. A meta-analysis of randomized controlled trials. $J$ Am Acad Dermatol, 55:537-8.

Garland SM. 2003. Imiquimod. Curr Opin Infect Dis, 16:85-9.

Garland SM, Sellors JW, Wikstrom A, et al. 2001. Imiquimod Study Group. Imiquimod 5\% cream is a safe and effective self-applied treatment for anogenital warts - results of an open-label, multicentre Phase IIIB trial. Int J STD AIDS, 12:722-9. 
Geisse J, Caro I, Lindholm J, et al. 2004. Imiquimod 5\% cream for the treatment of superficial basal cell carcinoma: results from two phase III, randomized, vehicle-controlled studies. J Am Acad Dermatol, 50:722-33.

Geisse JK, Rich P, Pandya A, et al. 2002. Imiquimod 5\% cream for the treatment of superficial basal cell carcinoma: a double-blind, randomized vehicle-controlled study. J Am Acad Dermatol, 47:390-8.

Gilliet M, Conrad C, Geiges M, et al. 2004. Psoriasis triggered by toll-like receptor 7 agonist imiquimod in the presence of dermal plasmacytoid dendritic cell precursors. Arch Dermatol, 140:1490-5.

Gilson RJ, Shupack JL, Friedman-Kien AE, et al. 1999. A randomized, controlled, safety study using imiquimod for the topical treatment of anogenital warts in HIV-infected patients. Imiquimod Study Group. AIDS, 13:2397-404.

Goldenberg G, Krowchuk DP, Jorizzo JL. 2006. Successful treatment of a therapy-resistant pyogenic granuloma with topical imiquimod 5\% cream. J Dermatolog Treat, 17:121-3.

Goorney BP, Polori R. 2004. A case of Bowenoid papulosis of the penis successfully treated with topical imiquimod cream 5\%. Int J STD AIDS, 15:833-5.

Gupta AK, Cherman AM, Tyring SK. 2004. Viral and nonviral uses of imiquimod: a review. J Cutan Med Surg, 8:338-52.

Gupta AK, Davey V, McPhail H. 2005. Evaluation of the effectiveness of imiquimod and 5-fluorouracil for the treatment of actinic keratoses: critical review and meta-analysis of efficacy studies. J Cutan Med Surg, 9:209-14.

Hadley G, Derry S, Moore RA. 2006. Imiquimod for actinic keratoses: systematic review and meta-analysis. J Invest Dermatol, 126:1251-5.

Hazen PG, Carney JF, Engstrom CW, et al. 2005. Proliferating hemangioma of infancy: successful treatment with topical $5 \%$ imiquimod cream. Pediatr Dermatol, 22:254-6.

Hengge UR, Cusini M. 2003. Topical immunomodulators for the treatment of external genital warts, cutaneous warts and molluscum contagiosum. Br J Dermatol, 149 Suppl 66:15-19.

Hughes PS. 2006. Treatment of lymphomatoid papulosis with imiquimod $5 \%$ cream. J Am Acad Dermatol, 54:546-7.

Jain S. 2006. Successful treatment of porokeratosis of Mibelli with imiquimod 5\% cream. Clin Exp Dermatol, 31:302-3.

Jo JH, Ko HC, Jang HS, et al. 2005. Infiltrative trichilemmal carcinoma treated with 5\% imiquimod cream. Dermatol Surg, 31:973-6.

Jo JH, Chin HW, Kim MB, et al. 2005. A case of eccrine poroma treated with 5\% imiquimod cream. J Dermatol, 32:691-3.

Kagy MK, Amonette R. 2000. The use of imiquimod 5\% cream for the treatment of superficial basal cell carcinomas in a basal cell nevus syndrome patient. Dermatol Surg, 26:577-8.

Kelly SC, Purcell SM. 2006. Imiquimod therapy for elastosis perforans serpiginosa. Arch Dermatol, 142:829-30.

Le T, Hicks W, Menard C, et al. 2006. Preliminary results of $5 \%$ imiquimod cream in the primary treatment of vulva intraepithelial neoplasia grade 2/3. Am J Obstet Gynecol, 194:377-80.

Mackenzie-Wood A, Kossard S, de Launey J, et al. 2001. Imiquimod 5\% cream in the treatment of Bowen's disease. J Am Acad Dermatol, 44:462-70.

Marks R, Gebauer K, Shumack S, et al. 2001. Australasian Multicentre Trial Group. Imiquimod $5 \%$ cream in the treatment of superficial basal cell carcinoma: results of a multicenter 6-week dose-response trial. $J \mathrm{Am}$ Acad Dermatol, 44:807-13.

Martin-Garcia RF. 2005. Imiquimod: an effective alternative for the treatment of invasive cutaneous squamous cell carcinoma. Dermatol Surg, 31:371-4.

Marty CL, Randle HW, Walsh JS. 2005. Eruptive epidermoid cysts resulting from treatment with imiquimod. Dermatol Surg, 31:780-2.

Mashiah J, Brenner S. 2005. Possible mechanisms in the induction of pemphigus foliaceus by topical imiquimod treatment. Arch Dermatol, 141:908-9.

Micali G, Dall'Oglio F, Nasca MR. 2003. An open-label evaluation of the efficacy of imiquimod $5 \%$ cream in the treatment of recalcitrant subungual and periungual cutaneous warts. J Dermatol Treat, 14:233-6.
Micali G, Lacarrubba F, Nasca MR, et al. 2003. The use of imiquimod 5\% cream for the treatment of basal cell carcinoma as observed in Gorlin's syndrome. Clin Exp Dermatol, 28(S1):19-23.

Micali M, Nasca MR, Musumeci ML. 2005. Treatment of an extensive superficial basal cell carcinoma of the face with imiquimod 5\% cream. Int J Tissue React, 27:111-14.

Micali G, Nasca MR, Tedeschi A. 2003. Topical treatment of intraepithelial penile carcinoma with imiquimod. Clin Exp Dermatol, 28(S1):4-6.

Miranda-Verastegui C, Llanos-Cuentas A, Arevalo I, et al. 2005. Randomized, double-blind clinical trial of topical imiquimod $5 \%$ with parenteral meglumine antimoniate in the treatment of cutaneous leishmaniasis in Peru. Clin Infect Dis, 40:1395-403.

Naylor MF, Crowson N, Kuwahara R, et al. 2003. Treatment of lentigo maligna with topical imiquimod. Br J Dermatol, 149 Suppl 66:66-70.

Patel GK, Goodwin R, Chawla M, et al. 2006. Imiquimod 5\% cream monotherapy for cutaneous squamous cell carcinoma in situ (Bowen's disease): a randomized, double blind, placebo-controlled trial. $J$ Am Acad Dermatol, 54:1025-32.

Patel PJ, Skinner RB Jr. 2006. Experience with keloids after excision and application of 5\% imiquimod cream. Dermatol Surg, 32:462.

Perry CM, Lamb HM. 1999. Topical imiquimod: a review of its use in genital warts. Drugs, 58:375-90.

Redondo P, Del Olmo J, Idoate M. 2004. Angiolymphoid hyperplasia with eosinophilia successfully treated with imiquimod. $\mathrm{Br} J$ Dermatol, 151:1110-11.

Rinne D, Linhart C, Schofer H. 2000. Lip papillomatosis in immunodeficiency: therapy with imiquimod. Br J Dermatol, 142:196-7.

Sauder DN, Skinner RB, Fox TL, et al. 2003. Topical imiquimod 5\% cream as an effective treatment for external genital and perianal warts in different patient populations. Sex Transm Dis, 30:124-8.

Sauder DN. 2003. Imiquimod: modes of action. Br J Dermatol, 149(Suppl 66):5-8.

Schalock PC, Kornik RI, Baughman RD, et al. 2006. Treatment of verrucous carcinoma with topical imiquimod. J Am Acad Dermatol, 54(5 Suppl):S233-5.

Scheinfeld N, Lehman DS. 2006. An evidence-based review of medical and surgical treatments of genital warts. Dermatol Online J, 12:3.

Schiller M, Metze D, Luger TA, et al. 2006. Immune response modifiers mode of action. Exp Dermatol, 15:331-41.

Schulze HJ, Cribier B, Requena L, et al. 2005. Imiquimod 5\% cream for the treatment of superficial basal cell carcinoma: results from a randomized vehiclecontrolled phase III study in Europe. Br J Dermatol, 152:939-47.

Shumack S, Gebaeuer K, Quirk C, et al. 2004. 5\% imiquimod cream for the treatment of a large superficial basal cell carcinoma. Arch Dermatol, 140:1286.

Shumack S, Robinson J, Kossard S, et al. 2002. Efficacy of topical 5\% imiquimod cream for the treatment of nodular basal cell carcinoma: comparison of dosing regimens. Arch Dermatol, 138:1165-71.

Smith KJ, Germain M, Skelton H. 2001. Squamous cell carcinoma in situ (Bowen's disease) in renal transplant patients treated with 5\% imiquimod and 5\% 5-fluorouracil therapy. Dermatol Surg, 27:561-4.

Smith KJ, Germain M, Yeager J, et al. 2002. Topical 5\% imiquimod for the therapy of actinic cheilitis. $J$ Am Acad Dermatol, 47:497-501.

Sterry W, Ruzicka T, Herrera E, et al. 2002. Imiquimod 5\% cream for the treatment of superficial and nodular basal cell carcinoma: randomized studies comparing low-frequency dosing with and without occlusion. Br J Dermatol, 147:1227-36.

Stockfleth E, Meyer T, Benninghoff B, et al. 2002. A randomized, double-blind, vehicle-controlled study to assess $5 \%$ imiquimod cream for the treatment of multiple actinic keratoses. Arch Dermatol, 138:1498-502.

Stockfleth E, Rowert J, Arndt R, et al. 2000. Detection of human papillomavirus and response to topical 5\% imiquimod in a case of stucco keratosis. Br J Dermatol, 143:846-50.

Taverna JA, Stefanato CM, Wax FD, et al. 2006. Adult cutaneous Langerhans cell histiocytosis responsive to topical imiquimod. $J$ Am Acad Dermatol, 54:911-13. 
Theos AU, Cummins R, Silverberg NB, et al. 2004. Effectiveness of imiquimod cream $5 \%$ cream for treating childhood molluscum contagiosum in a double-blind, randomized pilot trial. Cutis, 74:134-8,141-2.

Tyring S, Conant M, Marini M, et al. 2002. Imiquimod; an international update on therapeutic uses in dermatology. Int $J$ Dermatol, 41:810-16.

Vender RB, Goldberg O. 2005. Innovative uses of imiquimod. J Drugs Dermatol, 4:58-63.

Yi BA, Nirenberg MJ, Goldstein SM, et al. 2005. Chronic neuropathic pain associated with imiquimod: report of 2 cases. $J$ Am Acad Dermatol, 52:57-8.

Wolf IH, Smolle J, Binder B, et al. 2003. Topical imiquimod in the treatment of metastatic melanoma to skin. Arch Dermatol, 139:273-6.

Zalaudek I, Petrillo G, Argenziano G. 2005. Aphthous ulcers and imiquimod. J Am Acad Dermatol, 53:360-1. 
